\title{
TU Graz startet Christian-Doppler- Labor für Festkörperbatterien
}

Im Fokus des neuen CD-Labors steht die Reduktion der Grenzflächenwiderstände innerhalb der Festkörperbatterie. So soll der Energiespeicher fit für E-Fahrzeuge werden.

In den vergangenen Jahren wurde intensiv an Festkörperelektrolyten geforscht und Materialien entwickelt, die eine ähnlich hohe Ionenleitfähigkeit besitzen wie Flüssigelektrolyte. Batterien mit festen Elektrolyten, etwa aus Keramiken, erreichen höhere Energie- und Leistungsdichten als herkömmliche Lithium-Ionen-Batterien mit Flüssigelektrolyt und sind obendrein feuerfest. „Festkörperbatterien wären ein Riesenschritt in Richtung flächendeckende E-Mobilität“, so Daniel Rettenwander vom
Institut für Chemische Technologien von Materialien der TU Graz.

Bei der Implementierung von neu entwickelten Festkörperelektrolyten in LithiumIonen-Batterien zeigte sich aber schnell ein Problem: „An den Grenzflächen bilden sich hohe Widerstände aus, die einen schnellen Ionentransport zwischen den Elektroden verhindern und somit zu einem signifikanten Leistungsverlust führen. Dabei handelt es sich in den meisten Fällen um die Grenzflächen zwischen Festkörperelektrolyt und
Elektrodenmaterial sowie zwischen Partikeln des Elektrolyten selbst." Das will Rettenwander im neuen Christian-Doppler-Labor für Festkörperbatterien erforschen. Die Eröffnung fand gemeinsam mit dem Unternehmenspartner AVL am 12. November 2020 statt.

Kontakt:

TU Graz, Institut für Chemische Technologie von Materialien, Graz, Österreich, www.tugraz.at

Wir suchen Sie zum baldmöglichsten Zeitpunkt als

KERAMIKTECHNIKER/-MEISTER (m/w/d)

\section{DAS ERWARTET SIE}

Wir bieten lhnen eine interessante Vollzeittätigkeit bei gutem Betriebsklima, übertariflicher Bezahlung und gründlicher Einarbeitung.

\section{QUALIFIKATIONEN}

Vorraussetzungen für Ihre Bewerbung ist die abgeschlossene Ausbildung zum Techniker/Meister und Freude an selbstständigem Arbeiten.

\section{IHRE AUFGABEN}

Der vorrangige Aufgabenschwerpunkt liegt in der

Produktentwicklung und später auch in der Fertigung.

- Masse-/Glasurentwicklung

- Fertigungsverfahren durch Gießen und Pressen

- Trocknen, Glasieren und Brennen

Haben wir Ihr Interesse an dieser interessanten Aufgabe geweckt, dann richten Sie Ihre Bewerbung bitte an die Geschäftsleitung.

WIR FREUEN UNS AUF IHRE BEWERBUNG.

Gutbrod Keramik GmbH Medlinger Straße 7 89423 Gundelfingen
$T+499073997500$

$F+4990732030$

www.gutbrod-keramik.de

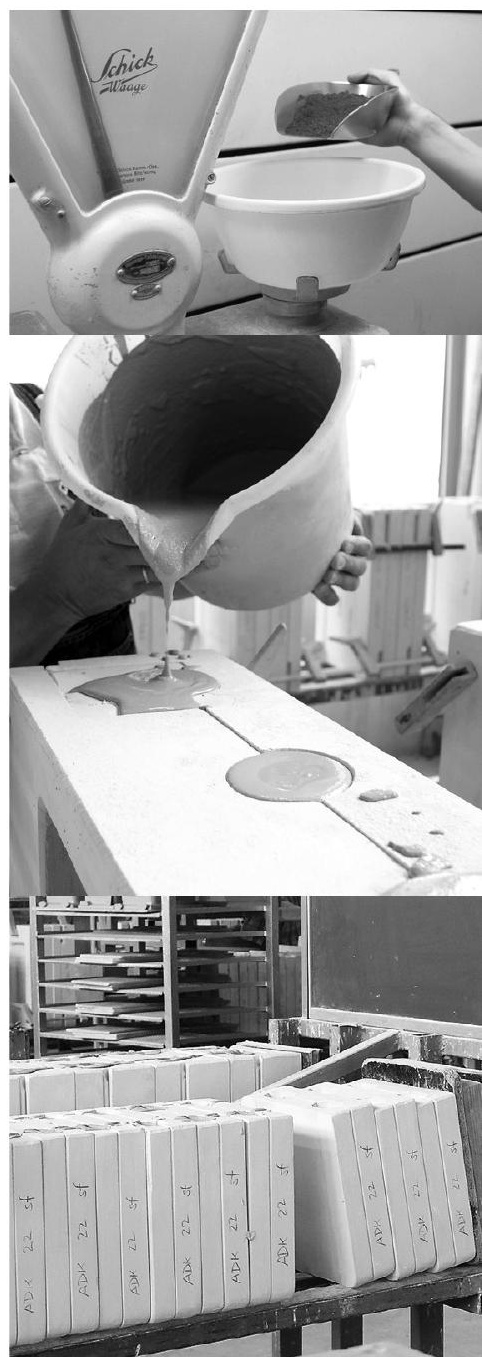

